\title{
Oligometastatic Pancreatic Cancer to the Liver in the Era of Neoadjuvant Chemotherapy: Which Role for Conversion Surgery? A Systematic Review and Meta-Analysis
}

\author{
Ottavia De Simoni ${ }^{1} \oplus$, Marco Scarpa ${ }^{2}$, Marco Tonello ${ }^{1} \oplus$, Pierluigi Pilati ${ }^{1}$, Francesca Tolin ${ }^{1}$, \\ Ylenia Spolverato ${ }^{2}$ and Mario Gruppo ${ }^{1, *(D)}$ \\ 1 Unit of Surgical Oncology of the Esophagus and Digestive Tract, Veneto Institute of Oncology IOV-IRCCS, \\ via Gattamelata, 64-35128 Padova, Italy; ottavia.desimoni@iov.veneto.it (O.D.S.); \\ marco.tonello@iov.veneto.it (M.T.); pierluigi.pilati@iov.veneto.it (P.P.); francesca.tolin@iov.veneto.it (F.T.) \\ 2 Department of Surgery, Oncology and Gastroenterology, University Hospital of Padua, via Giustiniani, \\ 2-35128 Padova, Italy; marco.scarpa@aopd.veneto.it (M.S.); yleniacamilla.spolverato@aulss6.veneto.it (Y.S.) \\ * Correspondence: mario.gruppo@iov.veneto.it
}

Received: 12 October 2020; Accepted: 14 November 2020; Published: 17 November 2020

Simple Summary: The development of new polychemotherapy regimens in patients with metastatic pancreatic cancer (mPDAC) have demonstrated significant improvement in clinical outcome, but evidence of the role of surgery following a favorable response to initial chemotherapy (IC) is still poor. The aim of the study is to analyze the impact of surgery following IC on survival in $\mathrm{mPDAC}$, focusing on oligometastatic disease to the liver. Data retrieved from available literature confirm increased survival in selected oligometastatic patients treated with surgery + IC compared to IC alone (23-56 months vs. 11-16.4 months), suggesting a potential role for conversion surgery in a tailored and multimodality approach to pancreatic cancer patients. Better knowledge of tumor biology and a wide consensus on diagnostic criteria could lead to the consideration of oligometastatic disease as a particular and different stage of disease.

Abstract: Background: the improved survival rates achieved using new polychemotherapy regimens in patients with metastatic pancreatic cancer (mPDAC) have suggested a potential role for surgery following a favorable response to initial chemotherapy (IC). The purpose of this systematic review is to summarize the available evidence on the role of surgery following IC in mPDAC, focusing on oligometastatic disease to the liver (lmPDAC). Methods: studies reporting on patients with ImPDAC undergoing surgery after IC were included. The main outcome was overall survival (OS). Results: six observational retrospective studies were included in the qualitative analysis. Data were retrieved on 2087 patients. The most common IC regimen in patients undergoing surgery was FOLFIRINOX (N 84, 73\%). Only three studies reported survival comparison among patients treated with IC+surgery vs. IC alone. Median OS varied from 23 to 56 months after conversion surgery vs. 11 to 16.4 months after IC alone. Conclusions: despite wide heterogeneity of chemotherapy regimens, different downstaging criteria and potential selection biases, patients with oligometastatic ImPDAC undergoing surgery after IC have significantly higher survival rates compared to patients treated with IC alone. Future trials are needed for definition of univocal criteria of downstaging, oligometastatic definition and indications for surgery.

Keywords: pancreatic cancer; oligometastatic disease; initial chemotherapy; conversion surgery; liver metastases 


\section{Introduction}

Pancreatic cancer is currently the third leading cause of cancer mortality in the USA, and projections to 2030 estimate that the disease will become the second leading cancer-related cause of death, after lung cancer [1-3]. Complete surgical resection with adjuvant systemic chemotherapy currently provides the only chance of a curative treatment option and long-term survival for pancreatic cancer patients. Unfortunately, only $15-20 \%$ of patients are diagnosed early enough to be resectable [4,5], and about $50 \%$ of the patients are diagnosed at a metastatic stage [6]. Furthermore, most of the patients with localized disease at diagnosis develop metastases at a later time; pancreatic cancer commonly spreads to the liver, lungs, lymph nodes, peritoneum and adrenal gland [7-9]. Overall, up to 70\% of patients show liver metastases from ductal adenocarcinoma of the pancreas (lmPDAC) along the course of their disease [10].

Nowadays, systemic chemotherapy plays the main role in patients with metastatic pancreatic cancer (mPDAC).

In the past, Gemcitabine has been the reference treatment for advanced pancreatic cancer [11]. Subsequently, in patients with advanced pancreatic cancer, one year survival has slightly improved because of the wider use of systemic chemotherapy and, more recently, the use of polychemotherapy regimens; the combination of chemotherapy with folinic acid, 5-fluorouracil, irinotecan and oxaliplatin (FOLFIRINOX) demonstrated a significant improvement in overall survival (OS) in subjects with good performance status, compared to Gemcitabine alone [12]. Similarly, an improvement in OS was demonstrated in patients with mPDAC treated with the combination Gemcitabine/Nab-Paclitaxel compared with Gemcitabine alone [13]. Moreover, adjuvant chemotherapy with gemcitabine plus capecitabine increased overall survival compared with gemcitabine alone after resection for pancreatic cancer [14].

Although palliative chemotherapy is the standard of care for patients with mPDAC, a review by Ghidini et al. suggested a rationale for additional liver surgical or locoregional treatment in oligometastatic PDAC, based upon a comprehensive summary of recent literature [15].

The term "oligometastases" was first proposed in 1995 and was related to patients with limited metastatic tumors; this concept was developed, according with the natural history of cancer progression, in order to describe an intermediate stage of disease, between localized and systemic conditions, and potentially suitable for additional local or locoregional treatments with curative intent [16].

Finally, the progressive advances in surgical techniques and results have allowed more patients to undergo surgical resection [17]. High-volume medical centers are increasingly proposing chemotherapy prior to surgery in order to downsize locally advanced tumours to obtain resectable neoplasm; the improved response rate and survival achieved using polychemotherapy regimens in patients with mPDAC have promoted the new concept of neoadjuvant therapy followed by resection for patients with locally advanced pancreatic cancer $[12,13]$.

New evidence has proposed FOLFOXIRI as a possible neoadjuvant therapy in selected advanced cases, in particular in oligometastatic disease [18-21]. In recent years, for patients with pancreatic cancer metastatic to the liver, there has been increased interest in exploiting strategies that have successfully been used for the treatment of oligometastases in other tumor types [15].

However, the management of the subgroup of patients with pancreatic cancer oligometastatic to the liver is still not clear and it should be considered a new challenge; furthermore, no randomized controlled trials are available, which have confirmed superiority of any of the applied therapies, and no evidence-based recommendation or international consensus is available on this topic yet.

The purpose of this systematic review is to summarize the available evidence and the role of initial chemotherapy in the treatment of mPDAC, focused on pancreatic cancer oligometastatic to the liver, in terms of multiple survival outcomes. 


\section{Materials and Methods}

\subsection{Study Design}

We performed a systematic literature search, study design and data analysis following PRISMA (Preferred Reporting Items for Systematic Reviews and Meta-Analyses) guidelines (see Supplemental Contents-PRISMA checklist, http://links.lww.com/MD/ B316) [22]. The protocol of this meta-analysis was registered with the prospective register of systematic reviews, PROSPERO (CRD42020135654).

\subsection{Search Strategy}

Five medical databases were consulted in this research: Medline, Embase, the Cochrane Database of Systematic Reviews, Web of Science and Scopus.

The primary search strategy included keywords and medical subject headings as follows: "Pancreatic cancer", "Pancreatic cancers", "Cancer of pancreas", "Cancer of the pancreas", "Duct cell carcinoma of the pancreas", "Ductal carcinoma of the pancreas", "Metastasis", "Metastases", "Neoplasm metastases", "Neoplasm metastasis", "Oligometastatic", "Neoadjuvant therapies", "Neoadjuvant therapy", "Neoadjuvant treatment", "Neoadjuvant treatments", "Chemotherapies", "Chemotherapy", "Cancer chemotherapy protocol", "Cancer chemotherapy protocols", "Metastasectomy", "Metastasectomies", "Pancreaticoduodenectomy", "Pancreaticoduodenectomies", "Distal pancreatic resection", "Pancreatic resection", "Extended pancreatic resection", "Lymphadenectomy", "Lymphadenectomies".

Articles from the search results have been selected independently by two authors (M.G and O.D.) following the inclusion and exclusion criteria. Any disagreements in study inclusion between the two authors was resolved by discussion. Only clinical studies written in English, Dutch, Spanish, German, French or Italian were selected. Studies with human patients 18 years of age and above were eligible for inclusion in the review. We did not include data quoted as unpublished or derived from abstracts.

\subsection{Selection Criteria and Outcome Measures}

We included all studies investigating a series of patients with oligometastatic pancreatic cancer who underwent pancreatic resection, metastasectomy and/or RFA after neoadjuvant chemotherapy or preoperative chemotherapy. In the case of duplicate publications that reported on (parts of) similar patient data, only the most recent and complete data sets were considered. According to the PICOS criteria, articles were selected in this systematic review according to the follow eligibility criteria: 1. Participants: adults with metastatic pancreatic adenocarcinoma; 2 . Intervention: pancreatic resection, metastasectomy and/or RFA after initial chemotherapy; 3. Comparison: patients with mPDAC undergoing only systemic chemotherapy; 4 . Outcomes: the main outcome measure was overall survival. Secondary outcome measures were: postoperative mortality and morbidity. We then focused on the subgroup of patients with pancreatic cancer oligometastatic to the liver. Meta-analyzed endpoint was overall survival. All relevant text, tables and figures were reviewed for data extraction.

\subsection{Quality Assessment of Retrieved Articles}

Two researchers independently assessed the quality of the articles using a quality evaluation list constructed with predefined parameters including: number of patients, accurate description of surgical procedures, accurate description of chemotherapy treatment and whether the study series was consecutive. Moreover, the Newcastle-Ottawa Scale (NOS) was utilized for assessing the quality of non-randomized studies in meta-analyses. 


\subsection{Data Extraction}

Data were extracted from original articles only using a set of predetermined parameters: demographic data, localization of cancer, histological details of adenocarcinoma, type of surgery, type of neoadjuvant chemotherapy, morbidity, 90 days mortality, overall survival.

\subsection{Statistical Analysis}

Review Manager 5.3 (Cochrane Collaboration, Nordic Cochrane Centre, Copenhagen, Denmark) was used for data analysis. All statistical measures were assessed with $p 0.05$ significance level. The $\mathrm{I}^{2}$ statistic was used to determine the heterogeneity of the included studies. Low, moderate and high heterogeneity was considered for levels of $\mathrm{I}^{2}$ values of $25-49 \%, 50-74 \%$, and above $75 \%$, respectively [23]. We used mean difference analysis. The graphical description of the statistical results was illustrated with forest plot. Evaluation of publication bias was determined with funnel plot analyses.

\section{Results}

\subsection{Study Selection}

After the literature search, 1132 relevant non-duplicated records had been identified, 920 of them were excluded based on the title or the abstract because they covered a variety of irrelevant topics. A further 198 articles were then excluded because 135 were case reports and 63 were reviews. Finally 6 studies, published between 2016 and 2019, matched the selection criteria and have been included in the quality analysis, as shown in Figure 1 [24-29]. Authors of potentially eligible studies with minor missing or incomplete data, were directly contacted and invited for additional information and data. Studies from authors that have answered with updated and complete data, have been included in the analysis. Therefore, 3 studies were included in the quantitative synthesis (meta-analysis) [25-27].

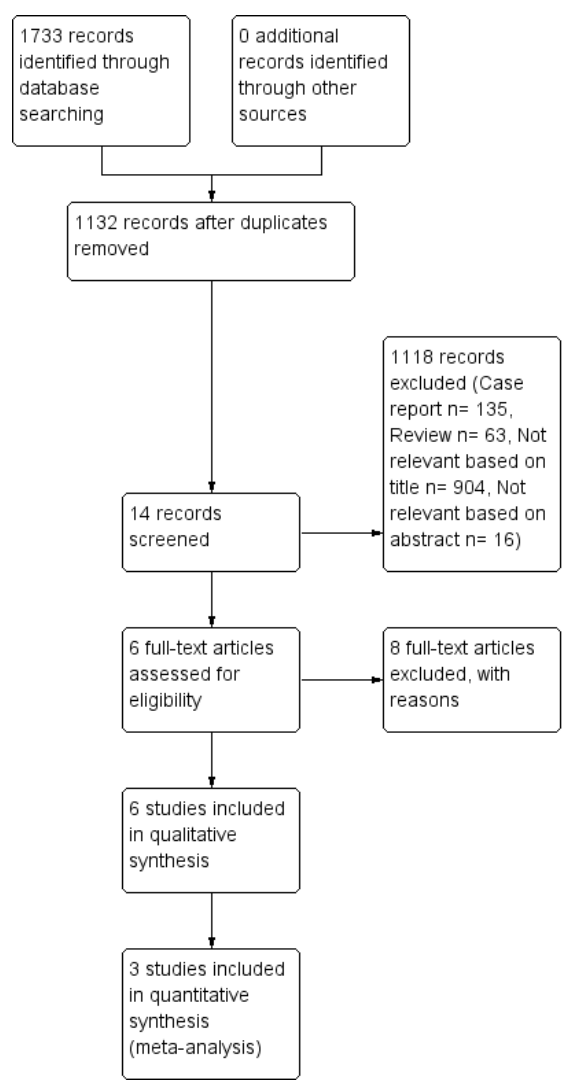

Figure 1. Flow chart of studies selection. 


\subsection{Study Characteristics and Patients Characteristics}

Six studies, all published between 2016 and 2019, matched the inclusion criteria and have been included in the qualitative analysis [24-29]. All the included studies were observational retrospectives. The demographic characteristics of the included studies are shown in Table 1.

Table 1. Characteristics of the studies.

\begin{tabular}{ccccccc}
\hline References & Publication Year & Country & Inclusion Period & Type of Study & Study Design & No. of Patients Analyzed \\
\hline Frigerio [24] & 2017 & Italy & $2007-2015$ & Retrospective & $\begin{array}{c}\text { Case series, } \\
\text { two centers }\end{array}$ & 535 \\
\hline Crippa [25] & 2016 & Italy & $2003-2013$ & Retrospective & $\begin{array}{c}\text { Case series, } \\
\text { two centers }\end{array}$ & 127 \\
\hline Tanaka [26] & 2019 & Germany & $2001-2017$ & Retrospective & $\begin{array}{l}\text { Case series, } \\
\text { one center }\end{array}$ & 101 \\
\hline Kandel [27] & 2018 & USA & $2005-2015$ & Retrospective & $\begin{array}{l}\text { Case series, } \\
\text { one center }\end{array}$ & 42 \\
\hline Wright [28] & 2016 & USA & $2008-2013$ & Retrospective & $\begin{array}{l}\text { Case series, } \\
\text { two centers }\end{array}$ & 1147 \\
\hline Byun [29] & 2019 & Japan & $2011-2017$ & Retrospective & $\begin{array}{l}\text { Case series, } \\
\text { one center }\end{array}$ & 337 \\
\hline
\end{tabular}

All studies had a quality score $\geq 6$, assessed using Newcastle-Ottawa score. Moreover all the studies reported an accurate description of surgical procedure and chemotherapy treatment, except for two $[27,29]$. The level of evidence and study quality have been summarized in Table 2.

Table 2. Level of evidence and quality assessment of the selected studies.

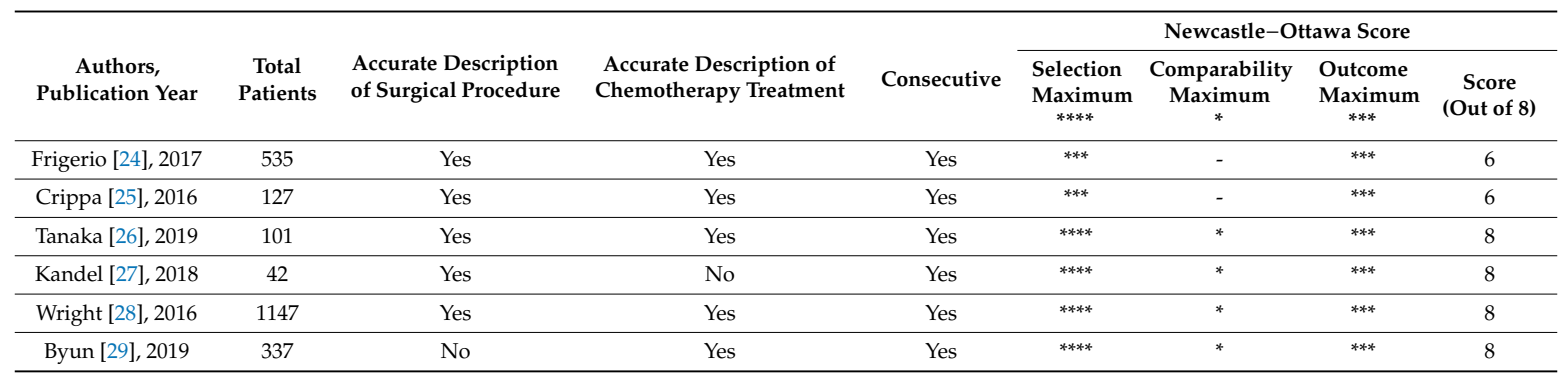

Newcastle-Ottawa Quality Assessment Scale for Cohort Study. $\left(^{*}\right.$ : the study met the criteria for a domain of the Newcastle-Ottawa Scale; -: the criteria were not met).

Patient characteristics are reported in Table 3. A total number of 2087 of patients with mPDAC were analyzed. Some 115 patients with mPDAC underwent surgery after IC. The most common chemotherapy regimen utilized in patients with mPDAC undergoing surgery was FOLFIRINOX, for $84(73 \%)$. In two studies, FOLFIRINOX was the only chemotherapy regimen used [26,29]. The interval between last chemotherapy and surgery varied from a median of 2 to 12 months. In all studies the main metastatic localization in patients undergoing surgery after IC was the liver for $85(79 \%)$ patients. Others metastatic localizations were: lung (N 7, 6\%), extraregional lymph nodes $(\mathrm{N} \mathrm{3}, 2 \%)$, peritoneum $(\mathrm{N} \mathrm{9,10 \% ).} \mathrm{Based} \mathrm{on} \mathrm{available} \mathrm{data} \mathrm{both} \mathrm{pancreaticoduodenectomy} \mathrm{and}$ distal pancreatectomy and total pancreatectomy were well represented. Surgery on liver metastases was heterogeneous, with a predominance of atypical resections.

As shown in Table 4, only 5 studies presented differentiated survival data for patients with pancreatic cancer metastatic to the liver undergoing IC [24-27,29]. The median age of all patients with ImPDAC ranged from 57.5 to 65 years. The median value of CA19.9 at diagnosis ranged from 210 to $1575 \mathrm{U} / \mathrm{mL}$ in patients who had undergone IC and surgery vs. $525-1846 \mathrm{U} / \mathrm{mL}$ in subjects treated with chemotherapy only. Other demographics and pathological parameters (gender, ECOG, tumor size) were not retrievable. Most authors described the rigorous criteria of response to initial chemotherapy used to select patients for surgery after IC. Only one article had, as a criteria of response to initial chemotherapy, a complete response of liver metastasis after initial chemotherapy [24]. The percentage 
decrease of CA19.9 in patients with ImPDAC undergoing surgery after IC varied from $92 \%$ to $97 \%$. The percentage decrease of CA19.9 in patients with ImPDAC undergoing only IC ranged from $42 \%$ to $60 \%$.

The most used chemotherapy regimen in patients who had undergone surgery after IC was FOLFIRINOX (N 50, 75\%). Limited to the available data, it was not possible to stratify survival outcomes based on different chemotherapy regimens. The number of total patients selected for surgery after IC was N 66 (8\%). The proportion of patients selected for surgery after IC varied from $4.5 \%$ to $52.6 \%$. Data on morbidity and mortality are shown in Table 4 . Only two articles described complications after surgery $[24,25]$. The median OS in patients with ImPDAC undergoing surgery after IC varied from 23.25 to 56 months. However, the median OS in patients with ImPDAC undergoing only IC varied from 11 to 16.4 months.

\subsection{Meta-Analysis: Survival Analysis}

Three studies described comparable patient groups in terms of outcome of survival and thus, a metanalysis was attempted [25-27]. All three studies investigated patients with pancreatic cancer metastatic to the liver undergoing IC followed by surgery or not and assessed an intervention group versus a control group. In these studies, cumulatively, 210 patients have been evaluated, of which 44 underwent surgery after IC and 166 underwent only chemotherapy. Heterogeneity resulted as significantly high among these studies (I2: $80 \%, p<0.007$ ) so the different dataset could not be pooled. As graphically shown in Figure 2, OS was longer in patients with pancreatic cancer with liver metastasis who underwent IC followed by surgery, compared to subjects treated only with chemotherapy (MD $-10.69,95 \%$ CI $-14.18--7.2, p<0.00001)$.

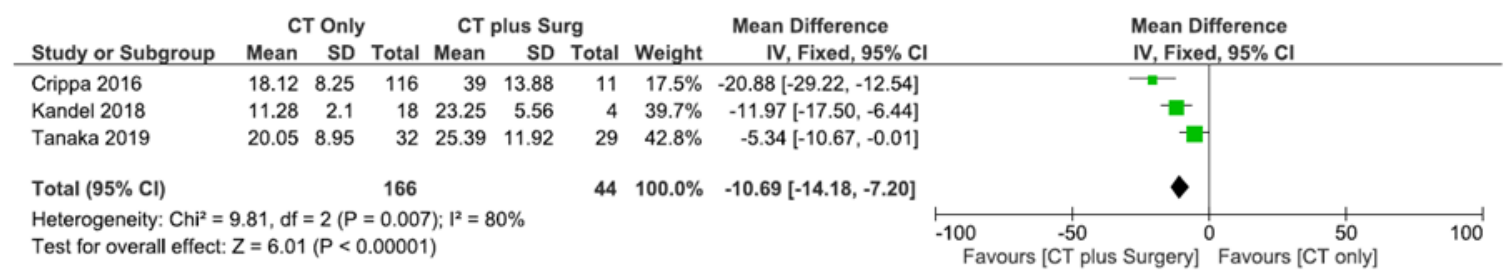

Figure 2. Forest plot of survival analysis.

\subsection{Sensitivity Analysis and Publication Bias}

Heterogeneity was high among studies $\left(\mathrm{I}^{2}=80 \%, p=0.007\right)$. Publication bias was evaluated with funnel plot analyses, as shown in Figure 3.

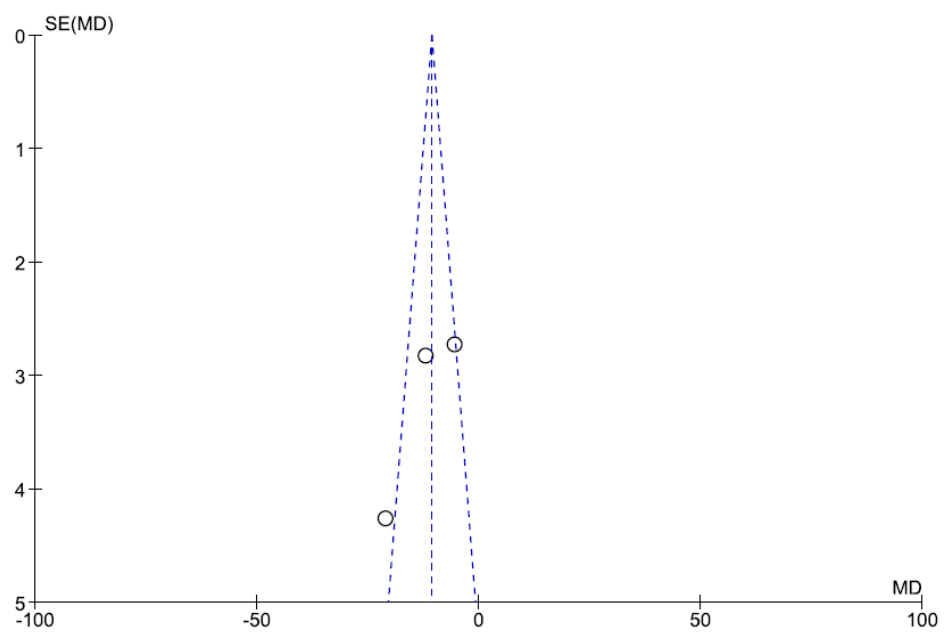

Figure 3. Funnel plot. 
Table 3. Characteristics of patients with mPDAC undergoing surgery after initial chemotherapy.

\begin{tabular}{|c|c|c|c|c|c|c|c|c|c|c|c|c|c|c|}
\hline \multirow[b]{2}{*}{ References } & \multirow[b]{2}{*}{ Patients, $\mathbf{N}$} & \multirow[b]{2}{*}{$\begin{array}{c}\text { Definition of } \\
\text { Oligometastatic } \\
\text { Disease or Inclusion } \\
\text { Criteria for Surgery } \\
\text { after IC }\end{array}$} & \multirow[b]{2}{*}{$\begin{array}{c}\text { Patients } \\
\text { Undergoing } \\
\text { Surgery after IC, } \\
\text { N (\%) }\end{array}$} & \multirow[b]{2}{*}{$\begin{array}{c}\text { Type of IC in Patients } \\
\text { Undergoing Surgery, } \mathbf{N} \\
(\%)\end{array}$} & \multirow[b]{2}{*}{$\begin{array}{l}\text { Median Interval } \\
\text { last IC-Surgery, } \\
\text { Months (range) }\end{array}$} & \multicolumn{4}{|c|}{$\begin{array}{l}\text { Main Metastatic } \\
\text { Localisation }\end{array}$} & \multirow[b]{2}{*}{$\begin{array}{c}\text { Type of } \\
\text { Surgery for } \\
\text { Primary } \\
\text { Lesion, N }\end{array}$} & \multirow[b]{2}{*}{$\begin{array}{l}\text { Type of Surgery } \\
\text { for Liver } \\
\text { Metastases N }\end{array}$} & \multirow[b]{2}{*}{$\begin{array}{l}\text { Adjuvant } \\
\text { CT N (\%) }\end{array}$} & \multirow[b]{2}{*}{$\begin{array}{l}\text { 30 Day } \\
\text { Mortality } \\
\text { N (\%) }\end{array}$} & \multirow[b]{2}{*}{$\begin{array}{l}\text { OS Months } \\
\text { (Range) }\end{array}$} \\
\hline & & & & & & $\stackrel{z}{z}$ & $\begin{array}{l}z \\
\substack{a b \\
\Xi \\
\Xi}\end{array}$ & 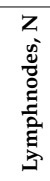 & 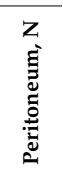 & & & & & \\
\hline Frigerio [24] & 535 & $\begin{array}{l}\text { Disappearance of liver } \\
\text { metastasis on } \\
\text { radiological } \\
\text { examination }\end{array}$ & $24(4)$ & $\begin{array}{l}\text { FOLFIRINOX N } 16 \text { (66), } \\
\text { GEM N } 5 \text { (21), Gemcitabine } \\
\text { + Nab-Paclitaxel N } 3 \text { (13) }\end{array}$ & $2(2-16)^{* * *}$ & 24 & 0 & 0 & 0 & $\begin{array}{l}\text { PD N } 14 \\
\text { DP N } 10\end{array}$ & None & N 15 (63) & $\begin{array}{c}\text { Not } \\
\text { specified }\end{array}$ & $56(36-75)^{* *}$ \\
\hline Crippa [25] & 127 & $\begin{array}{l}\text { Single metastasis } \\
\text { remaining after initial } \\
\text { chemotherapy }\end{array}$ & $11(8)$ & $\begin{array}{l}\text { FOLFIRINOX N3 (27), } \\
\text { GEMOX N2 (2), PDXG N1 } \\
\text { (9), PEFG N1 (9), PEXG N4 } \\
\text { (36) }\end{array}$ & $12(6-20) * * *$ & 11 & 0 & 0 & 0 & $\begin{array}{l}\text { PD N } 6 \\
\text { DP N } 5\end{array}$ & $\begin{array}{c}\text { Atypical } \\
\text { resection N 1, } \\
\text { Segmentectomy } \\
\text { N2 }\end{array}$ & $\begin{array}{c}\text { Not } \\
\text { specified }\end{array}$ & $\begin{array}{c}\text { Not } \\
\text { specified }\end{array}$ & $39 *$ \\
\hline Tanaka [26] & 101 & $\begin{array}{l}\text { Maximum of six } \\
\text { metastatic lesions. }\end{array}$ & $43(42)$ & FOLFIRINOX N43 (100) & Not specified & 30 & 1 & 3 & 7 & $\begin{array}{l}\text { PD N } 16 \\
\text { DP N } 19 \\
\text { TP N } 8\end{array}$ & Not specified & $\begin{array}{c}\text { N } 4 \text { (9), } \\
\text { Unknown } 9 \\
(21)\end{array}$ & $1(2)$ & $21.9(12.7-20.5)^{* * *}$ \\
\hline Kandel [27] & 42 & $\begin{array}{l}\leq 2 \text { metastatic tumors } \\
\text { total in liver or lung, } \\
\quad \text { each }<4 \mathrm{~cm}\end{array}$ & $6(14)$ & Not specified & Not specified & 4 & 0 & 0 & 2 & $\begin{array}{l}\text { PD N } 4 \\
\text { DP N } 2\end{array}$ & $\begin{array}{l}\text { Hepatic resection } \\
\text { N1, Hepatic } \\
\text { resection and } \\
\text { RFA n 2, } \\
\text { Radioembolization } \\
\text { N 1 } \\
\end{array}$ & $6(100)$ & 0 & $32 / 4(1.4-44.28)^{* *}$ \\
\hline Wright [28] & 1147 & Not specified & $23(2)$ & $\begin{array}{l}\text { FOLFIRINOX N14 (60.9), } \\
\text { Gemcitabine based } \\
\text { regimens N 9 (39.1) }\end{array}$ & $9.7(5.8-12.8)^{* * * *}$ & 16 & 6 & 0 & 2 & $\begin{array}{l}\text { PD } 15 \\
\text { DP } 8\end{array}$ & $\begin{array}{l}\text { Metastasectomy } \\
\text { N9 }\end{array}$ & $\begin{array}{c}\text { Not } \\
\text { specified }\end{array}$ & 0 & $18.2(11.8-35.5)^{* *}$ \\
\hline Byun [29] & 135 & $\begin{array}{l}\text { Single metastatic lesion } \\
\text { or resectable lesion }\end{array}$ & $8(5)$ & FOLFIRINOX 8 (100) & Not specified & NS & NS & NS & NS & Not specified & Not specified & $\begin{array}{c}\text { Not } \\
\text { specified }\end{array}$ & $\begin{array}{c}\text { Not } \\
\text { specified }\end{array}$ & $32 *$ \\
\hline
\end{tabular}

Values are * mean, ${ }^{* *}$ mean (s.d.), ${ }^{* * *}$ median (range). IC: initial chemotherapy; CT: chemotherapy; PD: pancreaticoduodenectomy; DP: distal pancreasectomy; TP: total pancreatectomy; GEM: gemcitabine; GEMOX: gemcitabine and oxaliplatin; FOLFIRINOX: oxaliplatin, irinotecan, fluorouracil and leucovorin; PEXG/PDXG: cisplatin, capecitabine, gemcitabine plus either epirubicin (PEXG) or docetaxel (PDXG); PEFG: cisplatin, epirubicin, fluorouracil and gemcitabine. NS: not specified. 
Table 4. Criteria of response to initial chemotherapy, inclusion criteria for surgery, IC regimens and outcomes of five series of patients with lmPDAC who underwent surgery after IC.

\begin{tabular}{|c|c|c|c|c|c|c|c|c|c|c|c|}
\hline \multicolumn{12}{|c|}{ Criteria of Response to IC } \\
\hline References & Patients & Primary Tumor & Liver Metastases & Level of CA19.9 & $\begin{array}{c}\text { Total Patients } \\
\text { with } \operatorname{lmPDAC}, \\
\mathbf{N}\end{array}$ & $\begin{array}{c}\text { Patients } \\
\text { Undergoing } \\
\text { Surgery after IC, } \\
\mathbf{N}(\%)\end{array}$ & $\begin{array}{c}\text { Type of Initial } \\
\text { Chemotherapy, N (\%) }\end{array}$ & $\begin{array}{c}\text { Complications } \\
\text { after Surgery } \\
\mathbf{N}(\%)\end{array}$ & $\begin{array}{c}\text { Median } \\
\text { Postoperative } \\
\text { Stay Days } \\
\text { (Range) }\end{array}$ & $\begin{array}{l}\text { OS in } \\
\text { Patients who } \\
\text { Underwent } \\
\text { IC+Surgery } \\
\text { Months } \\
\text { (Range) } \\
\end{array}$ & $\begin{array}{l}\text { OS in } \\
\text { Patients who } \\
\text { Underwent } \\
\text { IC alone } \\
\text { Months } \\
\text { (Range) } \\
\end{array}$ \\
\hline $\begin{array}{l}\text { Frigerio } \\
\text { [24] (2017) }\end{array}$ & $\begin{array}{l}\text { 1mPDAC who } \\
\text { responded to } \\
\text { systemic chemotherapy } \\
\text { and underwent } \\
\text { successful surgery. } \\
\end{array}$ & Not specified & $\begin{array}{l}\text { Disappearance of } \\
\text { liver metastasis } \\
\text { on radiological } \\
\text { examination }\end{array}$ & $\begin{array}{l}\text { Normalization or } \\
\text { significant reduction } \\
\text { of CA19.9 }\end{array}$ & 535 & $24(4.5)$ & $\begin{array}{c}\text { FOLFIRINOX N } 16 \\
\text { (66), } \\
\text { GEM N 5 (21), } \\
\text { Gemcitabine+Paclitaxel } \\
\text { N 3 (13) }\end{array}$ & $\begin{array}{l}\text { PF B N4 (16.5) } \\
\text { PF C N1 (4) } \\
\text { HEMORRHAGE } \\
\text { N1 (4) SEPSIS } \\
\text { N3 (12.5) }\end{array}$ & $13(7-40)$ & $56(36-75)^{\circ}$ & - \\
\hline $\begin{array}{l}\text { Crippa [25] } \\
\text { (2016) }\end{array}$ & $\begin{array}{l}1 \mathrm{mPDAC} \text { who } \\
\text { responded to systemic } \\
\text { chemotherapy and } \\
\text { underwent } \\
\text { successful surgery. }\end{array}$ & $\begin{array}{c}\text { Resectable or } \\
\text { borderline }\end{array}$ & $\begin{array}{l}\text { Complete or a } \\
\text { major radiological } \\
\text { response of the liver } \\
\text { metastases with a } \\
\text { single metastasis } \\
\text { remaining }\end{array}$ & $\begin{array}{l}\text { Major biochemical } \\
\text { response }\end{array}$ & 127 & $11(8.5)$ & $\begin{array}{c}\text { FOLFIRINOX N3 (27), } \\
\text { PDXG N1 (9), PEFG } \\
\text { N1 (9), PEXG N4 (36), } \\
\text { GEMOX N2 (2) }\end{array}$ & PF A N2 & 8 & $39^{\circ 0}$ & $11^{\circ 0}$ \\
\hline $\begin{array}{l}\text { Kandel [27] } \\
\text { (2018) }\end{array}$ & $\begin{array}{c}1 \mathrm{mPDAC} \text { who } \\
\text { underwent systemic } \\
\text { chemotherapy, } \\
\text { primary tumor } \\
\text { resection, } \\
\text { and metastasectomy } \\
\text { and/or RFA }\end{array}$ & Not specified & Not specified & Not specified & Not specified & $4(28)$ & Not specified & Not specified & Not specified & $23.25^{\circ 0}$ & $11.76^{\circ 0}$ \\
\hline $\begin{array}{l}\text { Tanaka [26] } \\
\text { (2019) }\end{array}$ & $\begin{array}{l}\text { ImPDAC undergoing } \\
\text { pancreasectomy and } \\
\text { metastasectomy after } \\
\text { FOLFIRINOX }\end{array}$ & $\begin{array}{l}\text { No tumor } \\
\text { progression, } \\
\text { technically } \\
\text { resectable disease } \\
\text { (resectable or } \\
\text { borderline resectable, } \\
\text { as defined by the } \\
\text { NCCN guidelines) }\end{array}$ & $\begin{array}{l}\text { A maximum of six } \\
\text { metastatic lesions }\end{array}$ & Not specified & 57 & $30(52.6)$ & $\begin{array}{l}\text { All patients } \\
\text { FOLFIRINOX }\end{array}$ & Not specified & $13(5-56)$ & $25.39^{\circ}$ & $16.4^{\circ}$ \\
\hline $\begin{array}{l}\text { Byun [29] } \\
\text { (2019) }\end{array}$ & $\begin{array}{l}1 \mathrm{mPDAC} \text { who } \\
\text { responded to systemic } \\
\text { chemotherapy and } \\
\text { underwent } \\
\text { successful surgery. }\end{array}$ & $\begin{array}{l}\text { Response to initial } \\
\text { chemotherapy per } \\
\text { RECIST criteria } \\
\text { (Version 1.1), } \\
\text { absence of local } \\
\text { tumor extension to } \\
\text { the major vessel }\end{array}$ & $\begin{array}{l}\text { Single metastatic } \\
\text { lesion or considered } \\
\text { as resectable }\end{array}$ & $\begin{array}{c}\text { Tumor markers } \\
\text { normalized } \\
\text { (or metabolic uptake } \\
\text { decreased in PET) }\end{array}$ & 80 & $1(1.25)$ & $\begin{array}{l}\text { All patients } \\
\text { FOLFIRINOX }\end{array}$ & None & Not specified & $23^{\circ 0}$ & $13^{\circ 0}$ \\
\hline
\end{tabular}

PF: pancreatic fistula (defined according to ISGPF criteria: grade A-B-C); ImPDAC: liver metastatic pancreatic adenocarcinoma; IC: initial chemotherapy; GEM: gemcitabine; GEMOX: gemcitabine and oxaliplatin; FOLFIRINOX: oxaliplatin, irinotecan, fluorouracil and leucovorin; PEXG/PDXG: cisplatin, capecitabine, gemcitabine plus either epirubicin (PEXG) or docetaxel (PDXG); PEFG: cisplatin, epirubicin, fluorouracil and gemcitabine. Values are overall survival from diagnosis, ${ }^{\circ}$ overall survival from surgery. 


\section{Discussion}

The insidious onset and aggressiveness of pancreatic cancer mean that only $15-20 \%$ of patients have the chance to receive curative surgery at first diagnosis [1,4]. Moreover, about $50 \%$ of patients with pancreatic cancer are diagnosed at metastatic stage [6]. Among these, the 5-year survival rate is only $2 \%$, while reported 1-year survival rates with Gemcitabine varied from 17 to $23 \%[3,11,12,30]$.

Despite advances in surgical techniques and oncology over the last decades, pancreatic cancer and its metastatic condition continues to pose major therapeutic challenges.

In recent years, the potential role of surgery in mPDAC has been explored. If some authors have stated that surgery is not beneficial in this setting, others, such as Shrinkade et al., provided initial and encouraging results, reporting a median survival of 13.8 months in patients with metastatic pancreatic cancer who had undergone pancreatic resection [31].

Gemcitabine alone was the cornerstone of medical treatment for nearly 15 years and demonstrated a positive impact on survival [11]. Afterwards, the introduction of polychemotherapy regimens has brought further benefits.

In recent years, a randomized phase III trial, MPACT, showed that a combination of gemcitabine and nab-paclitaxel (Gem + nabPTX) yielded a statistically significant survival benefit and response rate when compared with gemcitabine monotherapy [13].

Moreover, as underlined by PRODIGE/ACCORD 11, the FOLFIRINOX regimen has been evaluated in metastatic pancreatic adenocarcinoma and was an effective first-line treatment option, associated with an increase in overall survival, disease-free survival and response rate in comparison to gemcitabine alone [12,13]. Many centers assessed the efficacy of FOLFIRINOX and other polychemotherapy regimens as neoadjuvant treatment in locally advanced disease (LAPC) and, recently, in borderline resectable pancreatic cancer (BRPC). Surely, one of the main purposes of neoadjuvant therapy for $\mathrm{BRPC}$ is to achieve margin-negative resection and eliminate micrometastatic cells prior to surgery, preventing metastatic recurrence [32]. Miyasaka suggested that neoadjuvant with Gemcitabine plus nab-paclitaxel in BRPC potentially decreased recurrence during the intermediate-term postoperative period ( $33 \%$ vs. $77 \%$ ) with a significantly higher R0 resection rate $(100 \%$ vs. $77 \%, p=0.0100)$ [33]. Moreover, Ferrone underlined that FOLFIRINOX as neoadjuvant chemotherapy in LAPC or BRPC had a significant decrease in lymph node positivity ( $35 \%$ vs. $79 \%$ ), perineural invasion ( $72 \%$ vs. $95 \%$ ) and a significant increase in overall survival compared with resectable patients who underwent exploration without neoadjuvant treatment $(p=0.008)$ [34]. Furthermore, a recent randomized phase III trial ESPAC 4, showed that the adjuvant combination of gemcitabine and capecitabine could be the new standard of care following resection for pancreatic ductal adenocarcinoma [14].

At the same time, surgical techniques have also substantially improved, allowing more patients to undergo resection.

An emerging multimodality approach with a combination of surgery and greater use of polychemotherapy regimens has brought up the potential role of conversion surgery in pancreatic cancer. In fact, not only do $50 \%$ of the patients at the first diagnosis have metastatic disease but also a significant proportion of patients are unable to initiate adjuvant chemotherapy following pancreatectomy, frequently because of postoperative complications or rapid disease recurrence; this evidence has suggested the opportunity to administrate chemotherapy before surgery with the aim to increase the number of subjects treated with $\mathrm{CT}$ and better select patients who can benefit from a multimodal approach, with the longer survival and better postoperative and pathological outcomes reported for those patients who underwent curative intent surgery after neoadjuvant treatment [35-38].

Beside a significant improvement in chemotherapy regimens and surgical techniques, the "oligometastatic disease" has become increasingly important for researchers. In 1995, Hellman and Weichselbaum first proposed the clinically relevant condition of oligometastasis, developing the idea of an intermediate stage of disease, between localized and spread systemic conditions [36]. The multistep progression of cancer and a better knowledge of tumoral behavior have supported this concept [37-40]. 
The purpose of this systematic review was to analyze the role of conversion surgery after initial chemotherapy in the treatment of a particular condition of metastatic pancreatic cancer: the oligometastatic disease to the liver.

Conversion surgery is currently adopted in other oligometastatic neoplasms such as colorectal cancer, with the aim to cure or improve control of the disease in selected patients with major response to initial chemotherapy or favorable molecular profiles [41-43]; furthermore, other aggressive advanced neoplasms, previously considered not suitable for surgery, such as gastric cancer, are demonstrating good outcomes after conversion surgery following initial chemotherapy in selected cases [44]. This evidence lets us speculate that a better knowledge of tumor biology, with detection of prognostic molecular biomarkers, and a careful evaluation of response to chemotherapy could lead to an increase in conversion surgery rates and a better selection of subjects who can benefit from it.

The proper selection of surgical candidate patients after initial chemotherapy for ImPDAC is considered by most of the authors within this review the first and most important step. The decision for a surgical resection in patients with mPDAC to the liver has been made on a highly individual basis, including the patient's wishes, age, clinical status, local resectability and the individual risk of complications [45]. In addition, the evaluation of the initial Eastern Cooperative Oncology Group performance status (ECOG) and its re-evaluation during a neoadjuvant treatment is fundamental for prognostic purposes. Furthermore, articles that emphasize the importance of initial chemotherapy also highlight the importance of finding the most appropriate criteria of response to initial chemotherapy (Table 4).

Most of the authors share the fact that the downsizing criteria must include radiological criteria (response of the primary tumor and metastases) and biochemical criteria (decrease of the CA19.9 values). As suggested by Hong et al., the criteria of downsizing should be expanded in the future for the duration of the response and potential additional information with mutational analyses [19].

All the authors agree to define criteria for downsizing the achievement for resectability of the primitive neoplasm. However, the criteria for downsizing regarding the response of liver metastases are extremely heterogeneous: as reported in Table 4, Frigerio at al. considered surgical resection after restaging only in patients with radiological disappearance of liver metastasis, Crippa et al. performed resections in the case of a complete or major radiological response, while Tanaka accepted a maximum limit of six liver metastases [24-26].

From the data reported, only a small percentage of patients undergoing initial chemotherapy were finally selected for surgical treatment. From the available data only 66 patients out of $799(8.2 \%)$ undergoing initial chemotherapy met the criteria of downstaging for surgery.

Frigerio et al. described how, by adhering to strict downstaging criteria, few patients ( $\mathrm{N} 24,4.5 \%)$ could be selected for surgery on the primary neoplasm, reporting a median overall survival of 56 months (36-75) [24]. Crippa et al. considered eligible for surgery patients who had a good response to initial chemotherapy, with a maximum of one liver metastasis (N 11, 8,5\%), reporting a median overall survival of 39 months [25]. Tanaka et al. considered eligible for surgery patients with a maximum of six metastatic lesions, reporting a median overall survival of 25.39 months (Table 4) [26].

In meta-analysis, unfortunately, heterogeneity was significantly high among the studies (I2: 76\%, $p<0.02)$ so the different datasets could not be pooled. However, as graphically shown in Figure 3 , patients with ImPDAC who underwent chemotherapy and surgery were able to reach prolonged OS, compared to the solely chemotherapy group; nevertheless, no significant conclusion can be drawn from such data, because patients treated only with chemotherapy were not eligible for surgery, due to insufficient response to medical treatment. Furthermore, selected studies were retrospective case series and no perspective controlled trials are currently available.

Furthermore, considering the chemotherapy response, the heterogeneity of radiological downsizing the criteria of liver metastases goes hand in hand with the wide variability of definitions of oligometastatic disease among the authors, as underlined in Table 4 . The condition of oligometastatic disease is considered the starting point in the selection of patients, but actually there does not exist 
a unique definition, as demonstrated in reported articles where definitions are heterogeneous and mainly based on quantitative, dimensional and resectability criteria (Table 3).

Finally, as underlined by Reyes, the definition of oligometastasis has been gradually evolved and, in the absence of data to guide decisions, treatment of oligometastatic disease is still considered as a quality-of-life oriented approach, choosing personalized treatments, with a reasonable risk to benefit ratio and taking into account the patient's own will in guiding them toward conservative or aggressive therapy $[46,47]$.

Despite of heterogeneity of definitions, the oligometastatic disease in pancreatic cancer has undoubtedly become a source of debate regarding its potential treatment, claiming a wide consensus about its definition and classification in order to select patients with metastatic pancreatic cancer who can take advantage of a curative treatment.

As far as we know this is the first review focused on surgical treatment of pancreatic cancer oligometastatic to the liver after initial chemotherapy.

However, some limitations should be considered when interpreting our data: firstly, included studies are retrospective and with mono-institutional cohorts; secondly, as stated before, assessment of a definition of oligometastatic disease is still heterogenous and the definition of standard criteria of downsizing for surgery is lacking.

The adoption of universal criteria for definition of oligometastatic disease and for chemotherapy response assessment are needed to propose well-designed prospective studies, in order to evaluate the best therapeutic paths in this kind of patients.

\section{Conclusions}

Despite the wide heterogeneity of chemotherapy regimens, different intervals between chemotherapy and conversion surgery and different downsizing criteria, selected patients with ImPDAC who present good PS, a major response to initial chemotherapy and a favorable tumor biology could undergo conversion surgery after initial chemotherapy and reach significantly better survival rates than patients treated with chemotherapy alone.

This review confirms that oligometastatic pancreatic cancer can be considered a particular entity and a specific stage of disease, which deserves a specific evaluation, as previously reported $[36,46]$.

Larger multicentric perspective studies are needed to define and validate a widely accepted definition of oligometastatic disease and to confirm the potential benefit of conversion surgery after initial chemotherapy at this stage of disease.

Author Contributions: Conceptualization, O.D.S., P.P. and M.G.; methodology, O.D.S., M.T., M.S., M.G.; software, O.D.S. and M.G.; validation, O.D.S. and M.G.; formal analysis, O.D.S., M.T., F.T. and M.G.; investigation, O.D.S., F.T. and M.G.; resources, O.D.S., Y.S. and M.G.; data curation, O.D.S., M.T. and M.G.; writing-original draft preparation, O.D.S., Y.S. and M.G.; writing-review and editing, O.D.S. and M.G.; visualization, O.D.S., F.T. and M.G.; supervision, M.S., P.P. and M.G.; project administration, M.S., M.G. All authors have read and agreed to the published version of the manuscript.

Funding: This research received no external funding.

Conflicts of Interest: The authors declare no conflict of interest.

Disclosure: Preliminary data of this study have been presented as a conference abstract at the Digestive Disease Week DDW 2020 in Chicago, 2-5 May 2020.

\section{References}

1. Howlader, N. SEER Cancer Statistics Review, 1975-2014. Available online: https://seer.cancer.gov/archive/ Csr/1975_2014/ (accessed on 22 January 2020).

2. Rahib, L.; Smith, B.D.; Aizenberg, R.; Rosenzweig, A.B.; Fleshman, J.M.; Matrisian, L.M. Projecting Cancer Incidence and Deaths to 2030: The Unexpected Burden of Thyroid, Liver, and Pancreas Cancers in the United States. Cancer Res. 2014, 74, 2913-2921. [CrossRef] [PubMed] 
3. Cancer Facts \& Figures. 2016. Available online: https://www.cancer.org/research/cancer-facts-statistics/allcancer-facts-figures/cancer-facts-figures-2016.html (accessed on 22 January 2020).

4. Gillen, S.; Schuster, T.; Meyer zum Büschenfelde, C.; Friess, H.; Kleeff, J. Preoperative/Neoadjuvant Therapy in Pancreatic Cancer: A Systematic Review and Meta-analysis of Response and Resection Percentages. PLoS Med. 2010, 7, e1000267. [CrossRef]

5. He, J.; Ahuja, N.; Makary, M.A.; Cameron, J.L.; Eckhauser, F.E.; Choti, M.A.; Hruban, R.H.; Pawlik, T.M.; Wolfgang, C.L. 2564 resected periampullary adenocarcinomas at a single institution: Trends over three decades. НРВ 2014, 16, 83-90. [CrossRef] [PubMed]

6. Louvet, C.; Philip, P.A. Accomplishments in 2007 in the treatment of metastatic pancreatic cancer. Gastrointest Cancer Res. 2008, 2, S37-S41. [PubMed]

7. Disibio, G.; French, S.W. Metastatic patterns of cancers: Results from a large autopsy study. Arch. Pathol. Lab. Med. 2008, 132, 931-939. [CrossRef] [PubMed]

8. Kamisawa, T.; Isawa, T.; Koike, M.; Tsuruta, K.; Okamoto, A. Hematogenous metastases of pancreatic ductal carcinoma. Pancreas 1995, 11, 345-349. [CrossRef] [PubMed]

9. Embuscado, E.E.; Laheru, D.; Ricci, F.; Yun, K.J.; de Boom Witzel, S.; Seigel, A.; Flickinger, K.; Hidalgo, M.; Bova, G.S.; Iacobuzio-Donahue, C.A. Immortalizing the complexity of cancer metastasis: Genetic features of lethal metastatic pancreatic cancer obtained from rapid autopsy. Cancer Biol. Ther. 2005, 4, 548-554. [CrossRef]

10. Ryan, D.P.; Hong, T.S.; Bardeesy, N. Pancreatic adenocarcinoma. N. Engl. J. Med. 2014, 371, 1039-1049. [CrossRef]

11. Burris, H.A.; Moore, M.J.; Andersen, J.; Green, M.R.; Rothenberg, M.L.; Modiano, M.R.; Cripps, M.C.; Portenoy, R.K.; Storniolo, A.M.; Tarassoff, P.; et al. Improvements in survival and clinical benefit with gemcitabine as first-line therapy for patients with advanced pancreas cancer: A randomized trial. J. Clin. Oncol. 1997, 15, 2403-2413. [CrossRef]

12. Conroy, T.; Desseigne, F.; Ychou, M.; Bouché, O.; Guimbaud, R.; Bécouarn, Y.; Adenis, A.; Raoul, J.-L.; Gourgou-Bourgade, S.; de la Fouchardière, C.; et al. FOLFIRINOX versus gemcitabine for metastatic pancreatic cancer. N. Engl. J. Med. 2011, 364, 1817-1825. [CrossRef]

13. Von Hoff, D.D.; Ervin, T.; Arena, F.P.; Chiorean, E.G.; Infante, J.; Moore, M.; Seay, T.; Tjulandin, S.A.; Ma, W.W.; Saleh, M.N.; et al. Increased survival in pancreatic cancer with nab-paclitaxel plus gemcitabine. N. Engl. J. Med. 2013, 369, 1691-1703. [CrossRef] [PubMed]

14. Neoptolemos, J.P.; Palmer, D.H.; Ghaneh, P.; Psarelli, E.E.; Valle, J.W.; Halloran, C.M.; Faluyi, O.; O’Reilly, D.A.; Cunningham, D.; Wadsley, J.; et al. Comparison of adjuvant gemcitabine and capecitabine with gemcitabine monotherapy in patients with resected pancreatic cancer (ESPAC-4): A multicentre, open-label, randomised, phase 3 trial. Lancet 2017, 389, 1011-1024. [CrossRef]

15. Ghidini, M.; Petrillo, A.; Salati, M.; Khakoo, S.; Varricchio, A.; Tomasello, G.; Grossi, F.; Petrelli, F. Surgery or Locoregional Approaches for Hepatic Oligometastatic Pancreatic Cancer: Myth, Hope, or Reality? Cancers 2019, 11, 95. [CrossRef] [PubMed]

16. Kaneda, H.; Saito, Y. Oligometastases: Defined by prognosis and evaluated by cure. Cancer Treat. Commun. 2015, 3, 1-6. [CrossRef]

17. Kleeff, J.; Korc, M.; Apte, M.; La Vecchia, C.; Johnson, C.D.; Biankin, A.V.; Neale, R.E.; Tempero, M.; Tuveson, D.A.; Hruban, R.H.; et al. Pancreatic cancer. Nat. Rev. Dis. Primers 2016, 2, 16022. [CrossRef]

18. Lee, H.S.; Park, S.W. Systemic Chemotherapy in Advanced Pancreatic Cancer. Gut Liver 2016, 10, $340-347$. [CrossRef]

19. Hong, Y.; Rice, J.; Sharma, D.; Martin, R.C.G. The use of IRE in multi-modality treatment for oligometastatic pancreatic cancer. Am. J. Surg. 2018, 216, 106-110. [CrossRef]

20. Schneitler, S.; Kröpil, P.; Riemer, J.; Antoch, G.; Knoefel, W.T.; Häussinger, D.; Graf, D. Metastasized pancreatic carcinoma with neoadjuvant FOLFIRINOX therapy and R0 resection. World J. Gastroenterol. 2015, 21, 6384-6390. [CrossRef]

21. Hackert, T.; Sachsenmaier, M.; Hinz, U.; Schneider, L.; Michalski, C.W.; Springfeld, C.; Strobel, O.; Jäger, D.; Ulrich, A.; Büchler, M.W. Locally Advanced Pancreatic Cancer: Neoadjuvant Therapy with Folfirinox Results in Resectability in 60\% of the Patients. Ann. Surg. 2016, 264, 457-463. [CrossRef]

22. Moher, D.; Liberati, A.; Tetzlaff, J.; Altman, D.G.; The PRISMA Group. Preferred Reporting Items for Systematic Reviews and Meta-Analyses: The PRISMA Statement. PLoS Med. 2009, 6, e1000097. [CrossRef] 
23. Higgins, J.P.T.; Thompson, S.G.; Deeks, J.J.; Altman, D.G. Measuring inconsistency in meta-analyses. BMJ 2003, 327, 557-560. [CrossRef] [PubMed]

24. Frigerio, I.; Regi, P.; Giardino, A.; Scopelliti, F.; Girelli, R.; Bassi, C.; Gobbo, S.; Martini, P.T.; Capelli, P.; D'Onofrio, M.; et al. Downstaging in Stage IV Pancreatic Cancer: A New Population Eligible for Surgery? Ann. Surg. Oncol. 2017, 24, 2397-2403. [CrossRef] [PubMed]

25. Crippa, S.; Bittoni, A.; Sebastiani, E.; Partelli, S.; Zanon, S.; Lanese, A.; Andrikou, K.; Muffatti, F.; Balzano, G.; Reni, M.; et al. Is there a role for surgical resection in patients with pancreatic cancer with liver metastases responding to chemotherapy? Eur. J. Surg. Oncol. 2016, 42, 1533-1539. [CrossRef] [PubMed]

26. Tanaka, M.; Heckler, M.; Mihaljevic, A.L.; Sun, H.; Klaiber, U.; Heger, U.; Büchler, M.W.; Hackert, T. CT response of primary tumor and CA19-9 predict resectability of metastasized pancreatic cancer after FOLFIRINOX. Eur. J. Surg. Oncol. 2019, 45, 1453-1459. [CrossRef] [PubMed]

27. Kandel, P.; Wallace, M.B.; Stauffer, J.; Bolan, C.; Raimondo, M.; Woodward, T.A.; Gomez, V.; Ritter, A.W.; Asbun, H.; Mody, K. Survival of Patients with Oligometastatic Pancreatic Ductal Adenocarcinoma Treated with Combined Modality Treatment Including Surgical Resection: A Pilot Study. J. Pancreat. Cancer 2018, 4, 88-94. [CrossRef] [PubMed]

28. Wright, G.P.; Poruk, K.E.; Zenati, M.S.; Steve, J.; Bahary, N.; Hogg, M.E.; Zuriekat, A.H.; Wolfgang, C.L.; Zeh, H.J.; Weiss, M.J. Primary Tumor Resection Following Favorable Response to Systemic Chemotherapy in Stage IV Pancreatic Adenocarcinoma with Synchronous Metastases: A Bi-institutional Analysis. J. Gastrointest. Surg. 2016, 20, 1830-1835. [CrossRef] [PubMed]

29. Byun, Y.; Han, Y.; Kang, J.S.; Choi, Y.J.; Kim, H.; Kwon, W.; Kim, S.-W.; Oh, D.-Y.; Lee, S.H.; Ryu, J.K.; et al. Role of surgical resection in the era of FOLFIRINOX for advanced pancreatic cancer. J. Hepatobiliary Pancreat. Sci. 2019, 26, 416-425. [CrossRef]

30. Moore, M.J.; Goldstein, D.; Hamm, J.; Figer, A.; Hecht, J.R.; Gallinger, S.; Au, H.J.; Murawa, P.; Walde, D.; Wolff, R.A.; et al. Erlotinib plus gemcitabine compared with gemcitabine alone in patients with advanced pancreatic cancer: A phase III trial of the National Cancer Institute of Canada Clinical Trials Group. J. Clin. Oncol. 2007, 25, 1960-1966. [CrossRef]

31. Shrikhande, S.V.; Kleeff, J.; Reiser, C.; Weitz, J.; Hinz, U.; Esposito, I.; Schmidt, J.; Friess, H.; Büchler, M.W. Pancreatic resection for M1 pancreatic ductal adenocarcinoma. Ann. Surg. Oncol. 2007, 14, $118-127$. [CrossRef]

32. Tang, K.; Lu, W.; Qin, W.; Wu, Y. Neoadjuvant therapy for patients with borderline resectable pancreatic cancer: A systematic review and meta-analysis of response and resection percentages. Pancreatology 2016, 16, 28-37. [CrossRef]

33. Miyasaka, Y.; Ohtsuka, T.; Kimura, R.; Matsuda, R.; Mori, Y.; Nakata, K.; Kakihara, D.; Fujimori, N.; Ohno, T.; Oda, Y.; et al. Neoadjuvant Chemotherapy with Gemcitabine Plus Nab-Paclitaxel for Borderline Resectable Pancreatic Cancer Potentially Improves Survival and Facilitates Surgery. Ann. Surg. Oncol. 2019, 26, 1528-1534. [CrossRef] [PubMed]

34. Ferrone, C.R.; Marchegiani, G.; Hong, T.S.; Ryan, D.P.; Deshpande, V.; McDonnell, E.I.; Sabbatino, F.; Santos, D.D.; Allen, J.N.; Blaszkowsky, L.S.; et al. Radiological and surgical implications of neoadjuvant treatment with FOLFIRINOX for locally advanced and borderline resectable pancreatic cancer. Ann. Surg. 2015, 261, 12-17. [CrossRef] [PubMed]

35. Bilimoria, K.Y.; Bentrem, D.J.; Ko, C.Y.; Tomlinson, J.S.; Stewart, A.K.; Winchester, D.P.; Talamonti, M.S. Multimodality therapy for pancreatic cancer in the U.S.: Utilization, outcomes, and the effect of hospital volume. Cancer 2007, 110, 1227-1234. [CrossRef] [PubMed]

36. Hellman, S.; Weichselbaum, R.R. Oligometastases. J. Clin. Oncol. 1995, 13, 8-10. [CrossRef] [PubMed]

37. Chambers, A.F.; Groom, A.C.; MacDonald, I.C. Dissemination and growth of cancer cells in metastatic sites. Nat. Rev. Cancer 2002, 2, 563-572. [CrossRef]

38. Fidler, I.J. The pathogenesis of cancer metastasis: The "seed and soil" hypothesis revisited. Nat. Rev. Cancer 2003, 3, 453-458. [CrossRef]

39. Hanahan, D.; Weinberg, R.A. The hallmarks of cancer. Cell 2000, 100, 57-70. [CrossRef]

40. Hanahan, D.; Weinberg, R.A. Hallmarks of cancer: The next generation. Cell 2011, 144, 646-674. [CrossRef]

41. Shinozaki, K.; Yamada, T.; Nasu, J.; Matsumoto, T.; Yuasa, Y.; Shiraishi, T.; Nagano, H.; Moriyama, I.; Fujiwara, T.; Miguchi, M.; et al. A phase II study of FOLFOXIRI plus bevacizumab as initial chemotherapy for patients with untreated metastatic colorectal cancer: TRICC1414 (BeTRI). Int. J. Clin. Oncol. 2020. [CrossRef] 
42. Chen, D.; Zhang, X.; Gao, G.; Shen, L.; Xie, J.; Qian, X.; Wang, H. Should anti-EGFR mAbs be discontinued for conversion surgery in untreated right-sided metastatic colorectal cancer? A systematic review and meta-analysis. World J. Surg. Oncol. 2018, 16, 200. [CrossRef]

43. Hayashi, H.; Miyamoto, Y.; Higashi, T.; Hiyoshi, Y.; Yamao, T.; Uemura, N.; Matsumura, K.; Imai, K.; Yamashita, Y.-I.; Baba, H. CD44 expression enhances chemoresistance and implies occult micrometastases after conversion hepatectomy for initially unresectable colorectal liver metastases. Am. J. Transl. Res. 2020, 12, 5955-5966. [PubMed]

44. Mielko, J.; Rawicz-Pruszyński, K.; Skórzewska, M.; Ciseł, B.; Pikuła, A.; Kwietniewska, M.; Gęca, K.; Sęłak, K.; Kurylcio, A.; Polkowski, W.P. Conversion Surgery with HIPEC for Peritoneal Oligometastatic Gastric Cancer. Cancers 2019, 11, 1715. [CrossRef] [PubMed]

45. Tachezy, M.; Gebauer, F.; Janot, M.; Uhl, W.; Zerbi, A.; Montorsi, M.; Perinel, J.; Adham, M.; Dervenis, C.; Agalianos, C.; et al. Synchronous resections of hepatic oligometastatic pancreatic cancer: Disputing a principle in a time of safe pancreatic operations in a retrospective multicenter analysis. Surgery 2016, 160, 136-144. [CrossRef] [PubMed]

46. Reyes, D.K.; Pienta, K.J. The biology and treatment of oligometastatic cancer. Oncotarget 2015, 6, 8491-8524. [CrossRef] [PubMed]

47. Pagani, O.; Senkus, E.; Wood, W.; Colleoni, M.; Cufer, T.; Kyriakides, S.; Costa, A.; Winer, E.P.; Cardoso, F.; ESO-MBC Task Force. International guidelines for management of metastatic breast cancer: Can metastatic breast cancer be cured? J. Natl. Cancer Inst. 2010, 102, 456-463. [CrossRef] [PubMed]

Publisher's Note: MDPI stays neutral with regard to jurisdictional claims in published maps and institutional affiliations.

(C) 2020 by the authors. Licensee MDPI, Basel, Switzerland. This article is an open access article distributed under the terms and conditions of the Creative Commons Attribution (CC BY) license (http://creativecommons.org/licenses/by/4.0/). 